ISSN electrónico: 2172-9077

DOI: https://doi.org/10.14201/fjc-v22-25986

\title{
REVISANDO EL CINE DE ICÍAR Bollaín
}

\section{Reviewing the cinema of Iciar Bollain}

\section{Fernando GONZÁLEZ GARCÍA}

Profesor Titular. Universidad de Salamanca, España.

E-mail: fergogar@usal.es

(iD) https://orcid.org/0000-0002-5963-9269

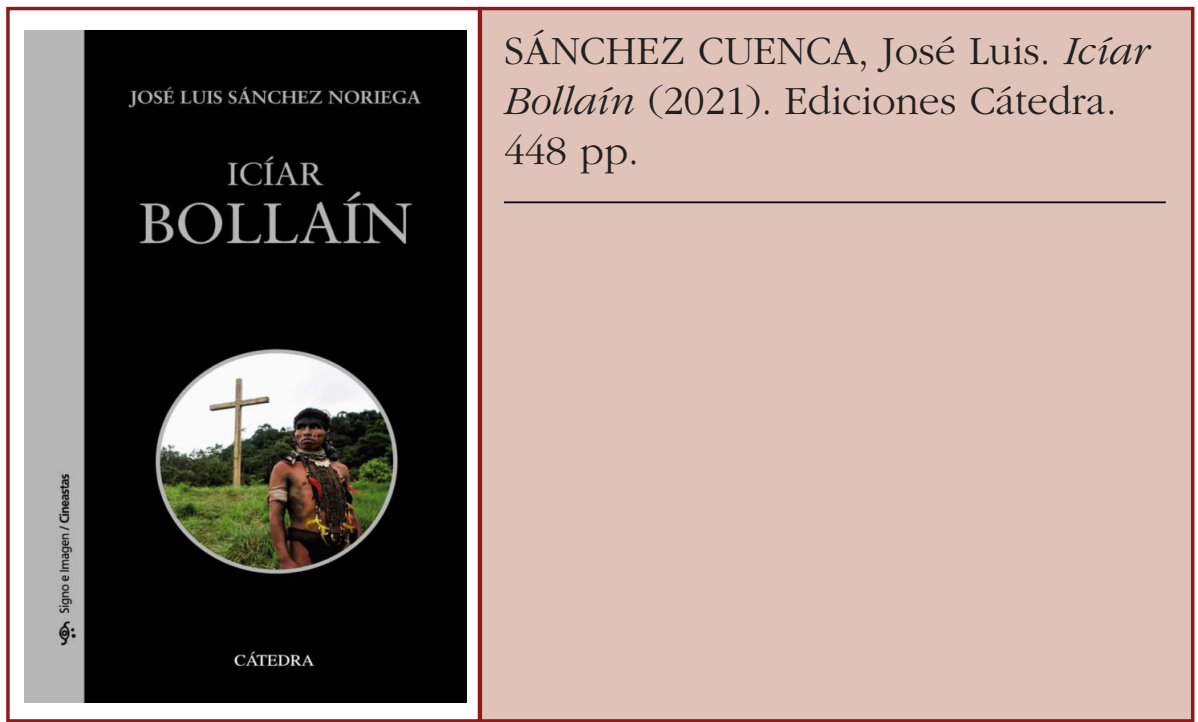

\section{Introducción}

A pesar del amplio reconocimiento académico internacional a la obra de Icíar Bollaín, patente en la enorme cantidad de artículos y capítulos de libros que se le han dedicado, no había todavía una monografía en español dedicada a revisar la obra completa de la directora. Sí habían aparecido previamente dos libros, uno en Francia (Lyazrhi, 2012), y otro en Reino Unido (Santaolalla, 2012): la editorial Cátedra, en su colección Signo e imagen/Cineastas, publica este 2021 un amplio volumen que viene a rellenar ese vacío y a actualizar la bibliografía existente, escrito por el catedrático de 
la Universidad Complutense, José Luis Sánchez Noriega. Teniendo en cuenta el corpus bibliográfico existente, al que hay que añadir las fuentes orales que ha recabado -entrevistas con la propia Icíar Bollaín y con un amplio número de personas con las que ha colaborado, desde directores de cine y escritores, hasta productores, músicos y montadores-, el autor compone un libro que cumple la difícil tarea de ser al mismo tiempo exhaustivo, divulgador y rigurosamente académico.

Ya en el apartado introductorio, aparte de una breve pero necesaria contextualización acerca de la generación que, por primera vez, en los años noventa, consigue que un importante número de mujeres debuten como directoras, se exponen los ejes temáticos que van a vertebrar el trabajo: el compromiso, como mujer, con los problemas de la sociedad contemporánea, un acercamiento a esta que pasa por el aprendizaje constante, y una idea de lo que es el cine que, partiendo del respeto a los personajes y a los actores, intenta trascender la polaridad entre un cine que o bien sería vehículo para la transmisión de contenidos o bien puro entretenimiento.

En el capítulo final, titulado "Estilo, personajes y sensibilidades: las claves de una estética", Sánchez Noriega incide en que el cine de Bollaín es un cine de autora. Si bien en la obra de Icíar Bollaín cada película tiene una manera particular de formalizarse, lo que superficialmente podría indicar la ausencia de un estilo, Sánchez Noriega demuestra con claridad que los -hasta el momento- diez largometrajes de Icíar Bollaín han ido surgiendo con el ritmo y dedicación propios de una creadora que crece y evoluciona, que son proyectos propios o asumidos por afinidad con unos valores cívicos y humanos, que cada película muestra un discurso original tanto a nivel formal como temático, alejado de los clichés de género, y, finalmente el conjunto muestra una visión del mundo personal (p. 370). La autora, por otra parte, está presente en todas las fases de realización de sus películas, desde la preproducción hasta el montaje final.

Un rasgo particular del modo de trabajar de Icíar Bollaín, que también es un tema recurrente en sus películas, es la confianza, al que hay que añadir la capacidad de colaboración. Confianza en el conocimiento del tema, recurriendo a la experiencia de personas que han vivido situaciones concretas, y a la de los guionistas, con los que muchas veces comparte el acercamiento a un problema, y confianza también en los actores y actrices que sabrán interpretar sus papeles, sin miedo a la posible improvisación, o a los avatares del rodaje. Todo a partir de un casting cuidadoso en el que se elige a los actores y actrices por su capacidad de empatizar con el personaje. Nunca considera a los actores como autómatas al servicio de una idea, ni al personaje como representación de esta. Actores y directora van constituyendo al personaje de modo dinámico. Si algo define el estilo de Icíar Bollaín, según Sánchez Noriega, es la capacidad para construir personajes en colaboración con los actores, para crear un realismo nuevo, proponiendo problemas más que dando lecciones, y por eso el autor insiste más de una vez en que las obras de Icíar Bollaín han tenido un recorrido que termina superando el del mercado, para llegar a formar parte de programas pedagógicos, no por dar soluciones, sino precisamente por su capacidad de formular preguntas.

Dada la importancia que la autora otorga al trabajo actoral, el libro dedica un amplio primer capítulo a la experiencia de Icíar Bollaín en este campo, titulado "Del oficio de actriz a la dirección de actores", donde repasa una a una las películas en las que participó, desde El sur (Víctor Erice, 1983), hasta Rabia (Sebastián Cordero, 2009), sin olvidar su aparición en cortometrajes y series de televisión. Como va a hacer en el resto del libro, cada película es resumida, examinada y finalmente se ofrece al lector 
un breve panorama de la recepción crítica en el momento de su estreno, sin que esta estructura interrumpa la narración que, aquí, es la del aprendizaje con distintos directores y actores, no solo del oficio de actriz, sino de las diferentes maneras de construir personajes y mundos de ficción.

Un capítulo aparte en este aprendizaje continuo que es la carrera de Icíar Bollaín como actriz, guionista, productora y directora, merece el del interés de la autora por el modo de trabajo de Ken Loach, al que dedicó un libro (Bollaín, 1996). En este capítulo, Sánchez Noriega analiza lo que Bollaín toma de Loach -a quien le acerca la sensibilidad social-: técnicas de ambientación, dirección de actores y rodaje, y lo que la separa de este "punto de partida", ensayando un intento de definición para el realismo de Bollaín: quizás se podría hablar, dice, de "realismo empático» o «realismo de la autenticidad", a sabiendas de lo que toda etiqueta tiene de reductora; se trata de reflejar personas y situaciones concretas «antes que el análisis sociológico o político», y "esta opción exige la autenticidad del personaje transmitida por el actor» (pp. 153-154).

A partir de este momento, con las premisas asentadas, el libro analiza obra por obra, comenzando por los cortometrajes y los spots publicitarios y siguiendo con los largometrajes, cada uno de los trabajos como directora de Icíar Bollaín, desarrollando la evolución de la autora y las manifestaciones de ese "realismo de la autenticidad» que desde el "arte del diálogo» de sus primeras películas (p. 218) no deja de traspasar fronteras, dialogando también con otras artes. La literatura, en su colaboración con Julio Llamazares para el guion de Flores de otro mundo (Icíar Bollaín, 1999), de la cual surgió, además de la película, un libro, coescrito con él (Bollaín, Llamazares, 2000), y sus adaptaciones de obras autobiográficas en Katmandú, un espejo en el cielo (Icíar Bollaín, 2011), y Yuli (Icíar Bollaín, 2018). Yuli es, también, una obra de carácter abiertamente intermedial, en la que la danza y la arquitectura tienen un papel fundamental. Como también lo tenía la pintura en Te doy mis ojos (Icíar Bollaín, 2003), película a la que ya se han dedicado varios artículos desde la perspectiva de los estudios intermediales, que no voy a citar, porque aparecen convenientemente referenciados en el libro.

El traspaso de fronteras no se da únicamente entre artes, sino que es también geográfico, y va, desde el espacio narrativo español que, ya desde Hola estás sola (Icíar Bollaín, 1995) incluye un personaje extranjero, el ruso con el que el personaje de Niña es capaz de comunicarse físicamente, sin otro lenguaje que medie, hasta las obras de carácter transnacional, desde los espacios geográficos abarcados hasta las productoras y la financiación implicadas, y en las que el problema de la comunicación en lenguas diversas se va haciendo cada vez más patente. La cuestión de la transnacionalidad es apuntada en el texto (p. 198), como una de las «señas de identidad» del cine de Icíar Bollaín.

El libro tiene dos finales: uno, el capítulo titulado como "Estilo, personajes y sensibilidades: las claves de una estética", donde Sánchez Noriega retorna sobre lo desgranado para reivindicar un concepto de autoría que problematiza el concepto heredado de puesta en escena, y otro, en el que, como anexos, se ofrecen el nuevo proyecto de la autora, con el título provisional de Maixabel, que tratará acerca de "las heridas del terrorismo y la superación del dolor de las víctimas» (p. 407), y una entrevista a Paul Laverty, guionista de trece títulos de Ken Loach, pareja de Icíar Bollaín y guionista de tres de sus películas, en la que Laverty aparte de incidir en el concepto de colaboración -en el que Sánchez Noriega insiste con ejemplos a lo 
largo de todo su trabajo- lo hace también en el término presupuesto. Hacer una película, como autora, en el caso de Bollaín, incluye la atención a lo económico, colaborando -de nuevo-, también en el control de los gastos, adecuando el proceso de elaboración de la película a esas posibilidades, que pueden ser cambiantes. Quizás, relacionando esto con su trabajo desde el proceso de documentación, la elaboración del guion, la dirección de los actores, y la adecuación de la puesta en escena a las necesidades concretas de cada obra, otro rasgo del modo de trabajar de Bollaín, en el que se detienen los montadores que han trabajado con ella, a los que el autor del libro ha entrevistado, y que se manifiesta en los resultados, sea el de la flexibilidad. Una flexibilidad que compagina con el rigor.

El libro de Sánchez Noriega es exhaustivo, también en la bibliografía. Empatiza, evidentemente, con la autora a la que dedica el trabajo: la dimensión social del cine ha estado siempre en sus trabajos individuales como crítico y como académico y en los proyectos de investigación que ha dirigido.

Si hubiera que hacer alguna objeción al volumen, sería únicamente la carencia de un índice analítico que permitiera al lector interesado retornar sobre obras y nombres yendo directamente a las páginas en las que son citados en este que ya es, a pesar de que la obra de Icíar Bollaín siga creciendo, un imprescindible libro de referencia.

\section{Bibliografía}

Bollaín, I. (1996). Ken Loach. Un observador solidario. Madrid: El País-Aguilar

Bollaín, I. \& Llamazares, J. (2000). Cine y Literatura. Reflexiones a partir de Flores de otro mundo. Madrid: Páginas de espuma.

Lyazrhi, N. (2012). Le cinema postmoderne espagnol. Réalisme et engagement d'une cinéaste humaniste. La libération de la femme come dépassement des stigmates sexuels. Toulouse: Université Toulouse Le Mirail.

Santaolalla, I. (2012). The Cinema of Icíar Bollaín. Manchester: Manchester University Press. 